\title{
Comparative Analysis of Different Facts Devices on Expanded Port Harcourt Network
}

\author{
Ajabuego O. G. ${ }^{1}$ \\ Electrical Engineering Department, \\ Port Harcourt, \\ Port Harcourt, Rivers state, Nigeria.
}

\author{
Olubiwe. M. ${ }^{2}$ \\ Dept. of Electrical Electronics University of Engineering \\ F.U.T.O, Owerri, Imo State, \\ Nigeria
}

\begin{abstract}
This work considered the impact of Flexible Alternating Current Transmission System (FACTS) devices on Port Harcourt Network. FACTS have been proffered in recent times as the best approach to curb reactive power imbalance. The FACTS devices used for the analysis are Thyristor Controlled Series Compensator (TCSC), Static Synchronous Compensator(STATCOM) and Unified Power Flow Controller (UPFC). The two methods considered for the justification of the FACTS devices are load flow and continuation power flow. Load flow was used to ascertain the voltage profile of the Network, while continuation power flow was used to know how much load the system can take without collapse (maximum loading). The results obtained showed that UPFC was preferred more than other FACTS devices when considering the loading parameter and voltage profile. When considering the real and reactive power losses, STATCOM shows best result. For the real and reactive power losses, STATCOM gave the best result of $0.6572 \mathrm{pu}$ and1.2345pu respectively as compared to TCSC $(0.8965 p u$ real power loss and $1.786 \mathrm{pu}$ reactive power loss) and UPFC $(0.6823$ pu real power loss and1.345pu reactive power loss). This shows that considering a minimal losses, STATCOM will be more preferable or suitable for the Network. UPFC, on the other hand, gave the best result for loading parameter of $1.9875 p u$ as compared to TCSC and STATCOM which gave a loading parameter of $1.0894 \mathrm{pu}$ and $1.321 \mathrm{pu}$ respective. The analysis shows that, using the best FACTS device for a Network will aid a proper efficiency of the Network.
\end{abstract}

Keywords: FACTS, Thyristor-Controlled, Static-Compensator, Unified-power, Load flow

\section{INTRODUCTION}

The electrical utility is probably the largest and most complex industry in the world. The electrical engineer, who researches in this industry, will encounter challenging problems in designing future power systems to deliver increasing amounts of electrical energy in a safe, clean and economical manner [1]. The provision of regular, affordable and efficient electricity is crucial for the growth, prosperity, national security as well as the rapid industrialization of any society. It is also a truism that any nation that desire to develop will not ignore the power sector. One of the prominent infrastructure deficit gaps in Nigeria is in the area of power. Nigerian power system has been so epileptic that her economy has been described as a generator economy [2]. The Manufacturers Association of Nigeria (MAN) and the National Association of Small Scale Industries (NASSI) estimated that their members spend an average of about N2billion (about $\$ 12$ million) weekly on self-power generation [3]. A series of power sector polls conducted by NOI Polls Ltd for the second quarter of 2013 revealed that about 130 million, representing 81 per cent, out of the 160 million Nigerians generated their own electricity through alternative sources to make up for irregular power supply. The study also showed a combined average of 69 per cent or 110 million of Nigerians experienced greater spending on alternative electricity supply [4].

A recent statistics on use of generating sets in the country released by the Director-General of Centre for Management Development, Dr. Kabir Usman, revealed that about 60 million Nigerians spent N1.6 trillion on generators annually "This Day Live, 2013". The endemic power crisis came as a result of the inability of the existing plants to meet the ever increasing demand. The supplydemand gulf exist because of myriads of reasons: obsolete and dilapidated plants with $36 \%$ of installed capacity being over 20 years old; $48 \%$ are over 15 years old and $80 \%$ are over 10 years old [5]. Other factors include lack of and poor maintenance of existing plants and poor managerial efficiency. The country's current power generation capacity fluctuates around $3,800 \mathrm{MW}$ and $4,500 \mathrm{MW}$ and the per capita electricity usage is 136 kilowatt/hour. Nigeria's electricity consumption on a per capita basis was among the lowest in the world when compared with the average per capita electricity usage in Libya, $4,270 \mathrm{kWh}$; India, 616kWh; China, 2,944kWh; South Africa, 4,803 $\mathrm{kWh}$; Singapore, $8,307 \mathrm{kWh}$; and the United States, 13,394kWh [6]. By comparison, South Africa, with a population of just 50 million, has an installed electricity generation capacity of over 52,000 MW. On a per capita consumption basis, Nigeria is ranked a distant 178th with 106.21 KWh per head, - well behind Gabon (900.00kWh); Ghana (283.65kWh); Cameroon (176.01kWh); and Kenya $(124.68 \mathrm{kWh})$ [3]. In curbing the problem of electricity supply in Nigeria, researchers have proposed several methods of which the closest to realize in the nearest future are FACTS devices. FACTS devices are the best approach to reduce or eradicate reactive power imbalance in Power system, which is the major cause of voltage instability. For the purpose of this study, three FACTS devices have been considered (i.e. TCSC, STATCOM and UPFC) for proper efficiency of the Network. This FACTS devices will be compared base on their response to voltage profile and addition of more load to the Network using continuation power flow (CPF). 


\section{LITTERATURE REVIEWED}

[7] explains the improvement of the Optimal Aim Strategy (OAS) for the design of a thyristor controlled series compensator controller has been proposed to enhance the inter-area transient stability of interconnected power systems. Due to some problems created in applying conventional OAS to the power system transient stability control and some solutions have been proposed to improve the conventional OAS and the analytic design procedures also have been proposed to achieve the desired performance.

[8] demonstrated the capability of the SSSC to control the line flow and to improve the power system stability. A control strategy of an SSSC to enlarge the stability region has been derived using the direct method. The effectiveness of the SSSC to extend the critical clearing time has been confirmed through simulation results on a single machine infinite bus system.

[9], presented a paper in which study and investigation is done on how UPFC affects the transmission system having series voltage and shunt current injection. UPFC provided better results than other devices and its advantages are also discussed.

[10], in this paper the use of Shunt Flexible AC Transmission System (FACTS) devices was determined and placed at the mid-point of a long transmission line and they gave an important role in controlling the reactive power flow to the power network and hence both the system voltage fluctuations and transient stability. This paper deals with the location of a shunt FACTS device to improve transient stability in a long transmission line with predefined direction of real power flow. [11], their paper dealt with improving the transient stability of long transmission line system by using SVC. In the present time power systems are being operated close to their stability limits due to economic and environmental reasons. Maintaining a stable and secure operation of a power system is a very important and challenging issue. Transient stability has been given much attention by power system researchers and planners in recent years and it is being regarded as one of major sources of power system insecurity.

\section{RESEARCH METHOD}

The methods considered for this research for the investigation of the best FACTS device for proper performance of the Port Harcourt Network are Load flow and CPF. Load flow was used to know the behavior of the Bus voltages at static load, while CPF was used to ascertain how much load can be added to the Network without causing any collapse to the Network. this simulation was done using Power System Analysis Toolbox (PSAT).

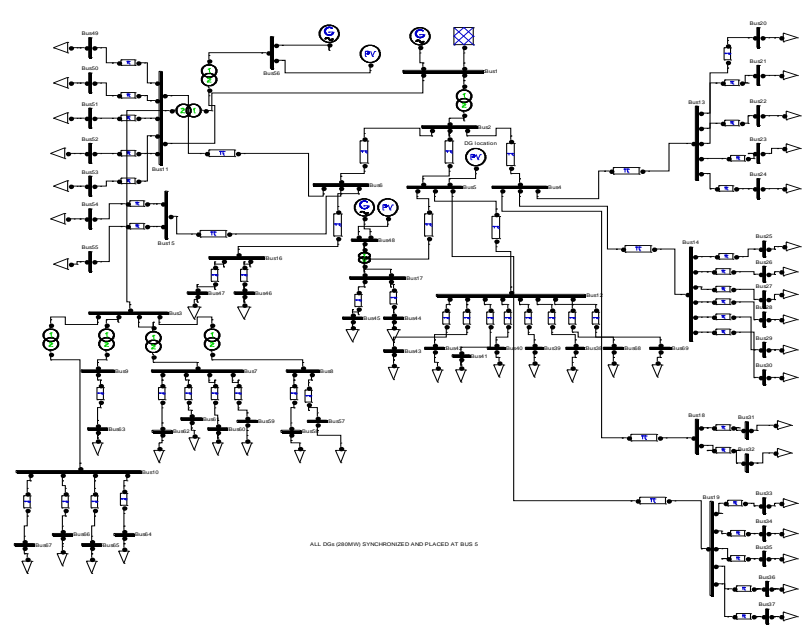

Figure 1: PSAT diagram of Port Harcourt Network

\section{A FACTS Devices}

The three FACTS devices considered for this work are TCSC, STATCOM and UPFC.

TCSC: this is introduced in the Port Harcourt Network to, increase dynamic stability of the power transmission system, improve voltage regulation and reactive power balance and improves load sharing between parallel lines.

The steady state model of the TCSC can be represented by a variable reactance $\mathrm{x}_{\mathrm{k}}{ }^{\mathrm{v}}$ in series with transmission line reactance $x_{k}$ as shown in fig. 2 .

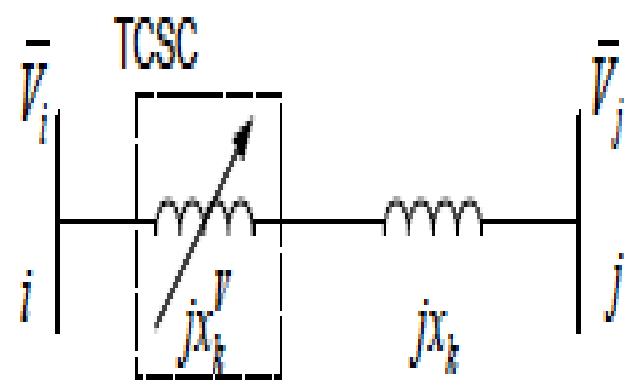

Figure 2: Static representation of TCSC

STATCOM: This is a controlled reactive-power source. It provides the desired reactive-power generation and absorption entirely by means of electronic processing of the voltage and current waveforms in a VSC. A STATCOM principle diagram is shown in Fig. 3. 


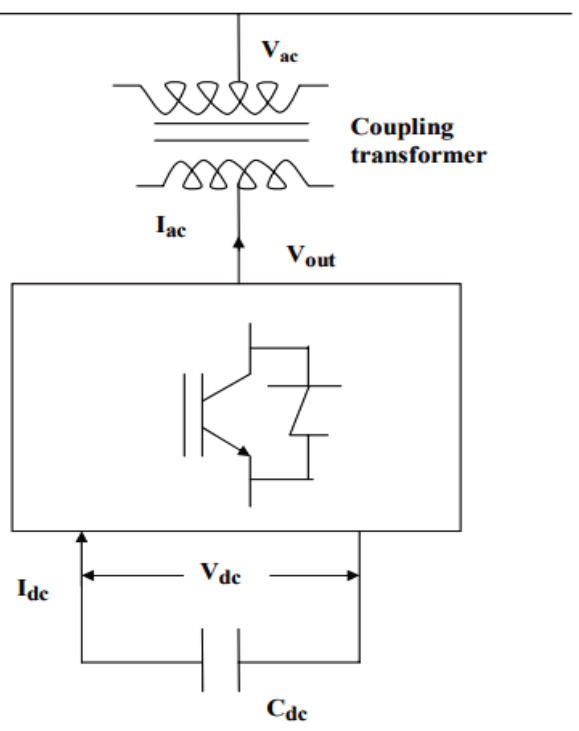

Figure 3: A functional model of STATCOM

The VSC is connected to a utility bus through shunt transformer. $\mathrm{V}_{\mathrm{ac}}$ is the bus voltage. $\mathrm{I}_{\mathrm{ac}}$ is STATCOM injected current. $\mathrm{V}_{\text {out }}$ is the VSC output voltage. $\mathrm{V}_{\mathrm{dc}}$ and $\mathrm{I}_{\mathrm{dc}}$ are the DC capacitor side voltage and current. An IGBT with back to back diode denotes the 3 arm IGBT bridge. Top three IGBTs are called as positive group and bottom three IGBTs are called as negative group IGBTs. The inverter operation takes place, when IGBTs conduct and converter operation takes place, when diodes conduct.

UPFC: The UPFC consists of two voltage source converters; series and shunt converter, which are connected to each other with a common dc link. Shunt converter (converter 1) or STATCOM is used to provide reactive power to the ac system, besides that, it will provide the dc power required for both inverters, while series converter (converter 2) or Static Synchronous Series Compensator (SSSC) is used to add controlled voltage magnitude line as shown in fig. 4. Each of the branches consists of a transformer and power electronic converter. These two voltage source converters shared a common dc capacitor. The real power can freely flow in either direction between the ac terminals of the two converters. In this respect, converter 2 provides the main function by injecting an $\mathrm{AC}$ voltage, at system frequency with variable magnitude and phase angle in series with the line. On the other hand, converter 1 is used primarily to provide the real power demanded by converter 2 at the common dc link [9]. UPFC tries to address the limitation of STATCOM and SSSC.

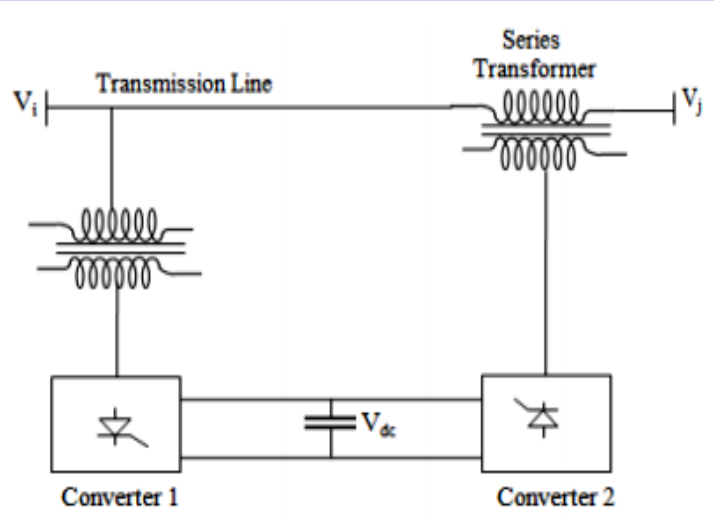

Figure 4: Configuration of UPFC [9]

B Load Flow Solution

There are two methods of solution for the load flow using Newton-Raphson method. The first method uses rectangular coordinates for the variables, while the method uses the polar coordinate form, but the polar coordinate method is widely used. The equation for the complex power at node $\mathrm{i}$ in the polar form is given in equation 1. Equations below gives the active and reactive powers at bus i. Reproducing this equations give

$$
\begin{aligned}
& S_{i}=P_{i}+j Q_{i}=V_{i} \sum_{k=1}^{n} Y_{i k}^{*} V_{k}^{*} \\
& S_{i}=\sum_{k=1}^{n}\left(V_{i} V_{k} Y_{i k}\right) \angle\left(\delta_{i}-\delta_{k}-\theta_{i k}\right) \\
& P_{i}=\sum_{k=1}^{n}\left(V_{i} V_{k} Y_{i k}\right) \cos \left(\delta_{i}-\delta_{k}-\theta_{i k}\right) \\
& Q_{i}=\sum_{k=1}^{n}\left(V_{i} V_{k} Y_{i k}\right) \sin \left(\delta_{i}-\delta_{k}-\theta_{i k}\right)
\end{aligned}
$$

Equation 3 and 4 can also be written as

$$
\begin{gathered}
P_{i}=\left(V_{i} V_{k} Y_{i i}\right) \cos \left(\theta_{i i}\right) \\
+\sum_{\substack{n=1 \\
n}}\left(V_{i} V_{k} Y_{i k}\right) \cos \left(\delta_{i}-\delta_{k}\right. \\
Q_{i}=-\left(V_{i} V_{i} Y_{i i}\right) \sin \left(\theta_{i i}\right) \\
+\sum_{k=1}^{n}\left(V_{i} V_{k} Y_{i k}\right) \sin \left(\delta_{i}-\delta_{k}-\theta_{i k}\right)
\end{gathered}
$$

We have $\Delta F=J \Delta X$

$$
\begin{gathered}
\text { If } \Delta P_{i}=P_{i(s p)}-P_{i(\text { cal })} \text { then } i=1,2,3, \ldots, n, \\
i \neq \text { slack } \quad(7) \\
\text { If } \Delta Q_{i}=Q_{i(s p)}-Q_{i(\text { cal })} \text { theni }=1,2,3, \ldots, n, \\
i \neq \text { slack, } i \neq P V
\end{gathered}
$$


Where the subscripts sp and cal denotes the specified and calculated values respectively, then equation $7 \& 8$ can be written as

$$
\left[\begin{array}{l}
\Delta P \\
\Delta Q
\end{array}\right]=\left[\begin{array}{cc}
H & N \\
M & L
\end{array}\right]\left[\begin{array}{l}
\Delta \delta \\
\Delta V
\end{array}\right]
$$

The off-diagonal and diagonal elements of the sub-matrices $\mathrm{H}, \mathrm{N}, \mathrm{M}, \mathrm{L}$ are determined by differentiating equation 9 with respect to $\delta$ and V. Off-diagonal elements of $\mathrm{H}$,

$$
\begin{gathered}
H_{i k}=\frac{\partial P_{i}}{\partial \delta_{k}}=\left(V_{i} V_{k} Y_{i k}\right) \sin \left(\delta_{i}-\delta_{k}-\theta_{i k}\right), i \\
\neq k
\end{gathered}
$$

Diagonal elements

$$
\begin{gathered}
H_{i k}=\frac{\partial P_{i}}{\partial \delta_{i}}=-V_{i} \sum_{\substack{\left.k=1 \\
\\
-\theta_{i k}\right)}}^{n}\left(V_{i} V_{k} Y_{i k}\right) \sin \left(\delta_{i}-\delta_{k}\right.
\end{gathered}
$$

Using equation 10 , we have

$$
\begin{aligned}
\frac{\partial P_{i}}{\partial \delta_{i}} & =-\left[Q_{i}+V_{i}^{2} Y_{i i} \sin \left(-\theta_{i}\right)\right] \\
H_{i i} & =-Q_{i}-V_{i}^{2} Y_{i i} \sin \left(-\theta_{i}\right) \\
& =-Q_{i}-B_{i i} V_{i}^{2}
\end{aligned}
$$

The off-diagonal and diagonal elements of $\mathrm{N}$ are given by,

$$
\begin{aligned}
\frac{\partial P_{i}}{\partial|V|}=V_{i} V_{k} \cos \left(\delta_{i}-\right. & \left.\delta_{k}-\theta_{i k}\right) \\
\frac{\partial P_{i}}{\partial|V|}=\left(2 V_{i} Y_{i i}\right) & \sin \left(\theta_{i i}\right) \\
& +\sum_{k=1}^{n}\left(V_{k} Y_{i k}\right) \sin \left(\delta_{i}-\delta_{k}\right. \\
& \left.-\theta_{i k}\right)
\end{aligned}
$$

The off-diagonal and diagonal elements of $\mathrm{M}$ are given by

$$
\begin{gathered}
\frac{\partial Q_{i}}{\partial \delta_{k}}=-\left(V_{i} V_{k} Y_{i k}\right) \cos \left(\delta_{i}-\delta_{k}-\theta_{i k}\right), i \\
\neq k \\
\frac{\partial Q_{i}}{\partial \delta_{k}}=\sum_{k=1}^{n}\left(V_{i} V_{k} Y_{i k}\right) \cos \left(\delta_{i}-\delta_{k}\right. \\
\left.-\theta_{i k}\right)
\end{gathered}
$$

The off-diagonal and diagonal elements of $\mathrm{L}$ are given by

$$
\begin{gathered}
\frac{\partial Q_{i}}{\partial \delta_{k}}=-\left(V_{i} Y_{i k}\right) \sin \left(\delta_{i}-\delta_{k}-\theta_{i k}\right), \quad i \\
\neq k
\end{gathered}
$$

$$
\begin{aligned}
\frac{\partial P_{i}}{\partial|V|}=-\left(2 V_{i} Y_{i i}\right) & \sin \left(\theta_{i i}\right) \\
& +\sum_{k=1}^{n}\left(V_{k} Y_{i k}\right) \sin \left(\delta_{i}-\delta_{k}-\theta_{i k}\right)
\end{aligned}
$$

It is seen from the element of the Jacobian that there is no symmetry in the results. Multiplying and dividing by $\mathrm{V}$ the voltage magnitude increment $\Delta \mathrm{V}$ to bring symmetry in the result, we have

$$
\begin{aligned}
& \Delta P=H \Delta \delta+(V N) \frac{\Delta V}{V} \\
& \Delta Q=M \Delta \delta+(V L) \frac{\Delta V}{V}
\end{aligned}
$$

Let $\mathrm{VN}=\mathrm{N}^{\prime}$ and $\mathrm{VL}=\mathrm{L}$, we can write

$$
\left[\begin{array}{l}
\Delta P \\
\Delta Q
\end{array}\right]=\left[\begin{array}{ll}
H & N^{\prime} \\
M & L^{\prime}
\end{array}\right]\left[\begin{array}{l}
\Delta \delta \\
\frac{\Delta V}{V}
\end{array}\right]
$$

In this case it will be seen that $H_{i k}=L_{i k}^{\prime}$ and $N_{i k}=-M_{i k}$

The property of symmetry of elements reduces the computer time and storage.

\section{Continuation Power Flow}

The continuation method is a mathematical path methodology used to solve systems of nonlinear equations. Using the continuation method, a solution branch around the turning point can be tracked without difficulties. It has been used for studies with approximations of the critical point in power systems. The Continuation Power Flow (CPF) captures this path-following feature by means of a predictor-corrector scheme that adopts locally parameterized continuation techniques to trace the PF solution paths. As shown in Figure 5, it starts from a known solution and uses a tangent predictor to estimate a subsequent solution which corresponds to a different value of the load parameter $\lambda$. Then, using the Newton-Raphson technique, the estimation value is corrected. For the parameterization, the local technique is used for identifying each point along the solution curve and makes part in avoiding singularity in the Jacobian. 


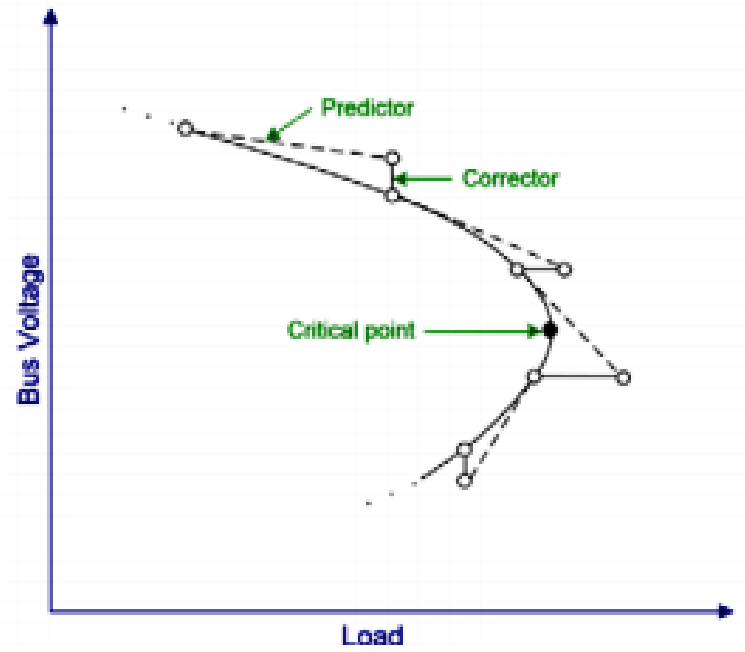

Figure 5: Predictor-corrector scheme used in the continuation power flow

This method will be used to ascertain the amount of load the Network could take without causing a collapse and the behavior of the Network at the collapse point.

To apply a local parametrization, the power flow equation is reformulated including a load parameter $\lambda$. The load is considered using a constant load model. In the new equation formulated, the load parameter varies in the range of 0 to $\lambda_{\text {critical }}$, where $\lambda=0$ corresponds to the base care and $\lambda$ $=\lambda_{\text {citical }}$ corresponds to the critical load. In general, the new equations forms, for each bus $i$ are shown in equations 23 and 24 below;

$$
\begin{aligned}
& \Delta P_{i}=P_{G i}(\lambda)-P_{L i}(\lambda)-P_{\tau I}=0 \\
& \Delta Q_{i}=Q_{G i}(\lambda)-Q_{L i}(\lambda)-Q_{\tau I}=0
\end{aligned}
$$

Where $\mathrm{i}, \mathrm{j}, \tau$ denotes the load, generation and injection for each bus. The new network will be subjected to NewtonRaphson power flow analysis until it gets to the critical load.

\section{RESULT}

The simulation of the work was done using MATLAB 7.9 PSAT to ascertain the load flow and CPF results. The result shows the voltage profile, real and reactive power losses and the loading parameter.

Table 1: Summary of result for the three FACTS devices

\begin{tabular}{|l|l|l|l|l|}
\hline FACTS & $\begin{array}{l}\text { Voltage } \\
\text { violation }\end{array}$ & $\begin{array}{l}\text { Real } \\
\text { power } \\
\text { loss }(\mathrm{pu})\end{array}$ & $\begin{array}{l}\text { Reactive } \\
\text { power loss } \\
(\mathrm{pu})\end{array}$ & $\begin{array}{l}\text { Loading } \\
\text { parameter } \\
(\mathrm{pu})\end{array}$ \\
\hline TCSC & 6 & 0.8965 & 1.786 & 1.0894 \\
\hline STATCOM & 5 & 0.6572 & 1.2345 & 1.321 \\
\hline UPFC & 4 & 0.6823 & 1.345 & 1.9875 \\
\hline
\end{tabular}

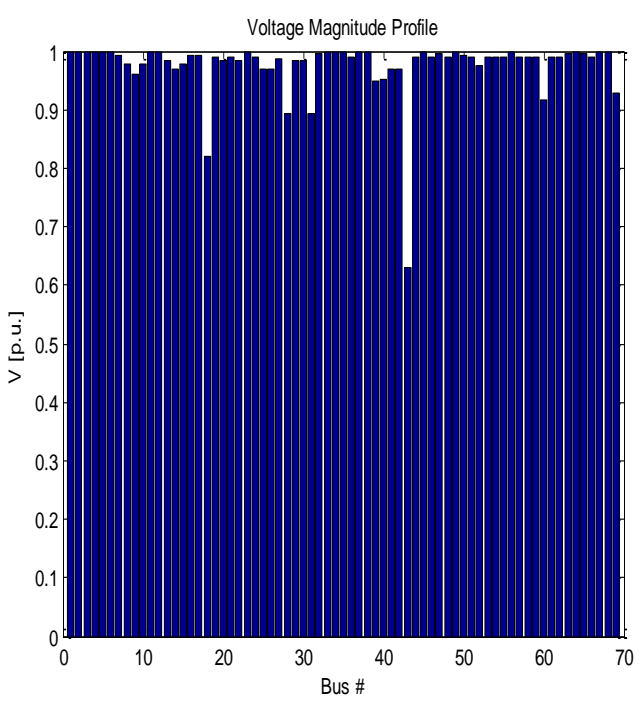

Figure 6: Voltage profile for TCSC

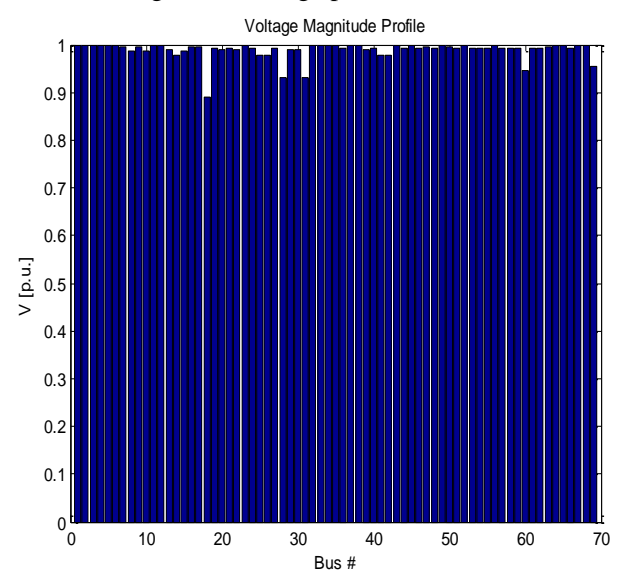

Figure 7: Voltage profile for STATCOM

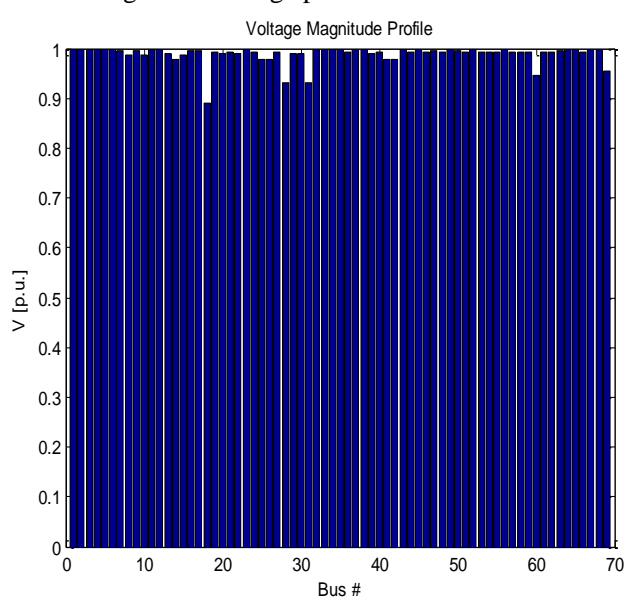

Figure 8: Voltage profile for UPFC

\section{$\mathrm{V} \quad$ DISCUSSION}

The result for the voltage profile, real and reactive power losses and loading parameter is shown in Table 1. Comparing the voltage violation as shown in the table and Figures 6, 7 and 8 shows that the best FACTS to consider 
is UPFC giving a voltage violation of 4 Buses as compared to TCSC and STATCOM which gave a voltage violations of 6 and 5 respectively.

For the real and reactive power losses, STATCOM gave the best result of $0.6572 \mathrm{pu}$ and1.2345pu respectively as compared to TCSC $(0.8965 \mathrm{pu}$ real power loss and $1.786 \mathrm{pu}$ reactive power loss) and UPFC (0.6823pu real power loss and1.345pu reactive power loss). This shows that considering a minimal losses, STATCOM will be more preferable or suitable for the Network.

UPFC, on the other hand, gave the best result for loading parameter of $1.9875 \mathrm{pu}$ as compared to TCSC and STATCOM which gave a loading parameter of $1.0894 \mathrm{pu}$ and $1.321 \mathrm{pu}$ respective.

\section{CONCLUSION}

The work shows a clear comparative analysis of different FACTS device for an effective performance of the Port Harcourt Network. According to the result gotten, UPFC can be suggested as the best FACTS device suitable for the Port Harcourt Network due to its low voltage violations and ability to accept more power as compared, which are the major factor considered when choosing an efficient and economic power supply. Also, its deviation in real and reactive power loss as compared to STATCOM is significantly small, though STATCOM gave the best result considering the real and reactive power losses.

\section{REFERENCE}

[1] L. Lawal, (2013). "Nigeria: A case Study in Power Shortages". International Journal of Economy, Management and Social Sciences 2(6), Pages: 410-418

[2] A.H. Ekpo, (2009). 'The Global Economic Crisis and the Crises in the Nigerian Economy', Presidential Address to the 50th Conference of the Nigerian Economic Society, September, AbujaNigeria

[3] Anyanrouh, F. (2013)."The Challenges of the Nigerian electric power reform.Vanguard".Retrieved from http://www.vanguardngr.com/2013/02/the-challenges-of-thenigerian-electric-power-sector-reform-1/

[4] S. Obasi, and C. Ayansina, (2014). "Nigeria: Power Supply Worsens in Q4 2013 - NOI Polls". Vanguard Retrieved from http://www.vanguardngr.com/2014/01/power-supply-worsens-q42013-noi-polls

[5] A.F. Adenikinju, (2003), “Electric Infrastructure failures in Nigeria: A survey based analysis of the costs and adjustment responses', Retrieved April, 2009. www.sciencedirect.com/science.

[6] O. Nnodim, (2014). "Power distribution firms owe government NERC". Punch. Retrieved from http://www.punchng.com/business/business-economy/powerdistribution- firms-owe-govt-nerc

[7] G. Glanzmann (2005). "FACTS: Flexible AC Transmission Systems", EEH - Power Systems Laboratory, ETH Zürich.

[8] P. Amaize, A. Adoghe, C. Awosope, and A. Airoboman, (2017). "a review of the application of FACTS device on Nigeria 330kV Transmission system,” Journ. Of Eng. And App. Sci., Vol. 12, Covenant University, Otta, Nigeria

[9] V.P. Suvarna, and M. Kalpesh, (2017).“A review on implementation of UPFC for improvement of active power flow capability in power system using IEEE 14 bus system," Int. Res. Journ.Of Eng. And Tech., Vol. 4, Maharashtra, India.

[10] Sidhartha, (2010), "Numerical method for online power system load flow analysis; energy certs US, P 235 -241

[11] R. Kamdar, M. Kumar and G. Agnihotri, (2014). "Transient stability analysis and enhancement of ieee-9 bus system", Electrical \& Computer Engineering: An International Journal (ECIJ) Volume 3, Number 2. 